\section{A 90 años de la creación de la primera Escuela de Trabajo Social en Chile y Latinoamérica, por el Dr. Alejandro del Río}

\section{Ninety years after the foundation of the first School of Social Work in Chile and Latin America by Alejandro del Río M.D.}

\section{Sr. Editor:}

En el año 2015 se cumplen 90 años desde que el destacado médico salubrista Alejandro del Río impulsara la creación de la primera Escuela de Servicio Social en Chile, fundada el 4 de mayo de 1925 y reconocida como la primera unidad especializada de formación social en Latinoamérica. La Escuela dependía de la Junta Nacional de Beneficencia y Asistencia Social, iniciativa del Estado destinada a atender las necesidades médico sociales de la población de menores recursos. Una de las preocupaciones centrales de la entidad era optimizar los esfuerzos sanitarios a través de la organización profesional de la asistencia social. Por tanto, el objetivo central de la escuela fue "formar visitadoras sociales que hicieran posible la sistematización de la asistencia en el país y colaboraran con el médico y los servicios e instituciones de beneficencia en la atención profesional de las necesidades de la población"'.

La tarea formativa contó con los conocimientos de asistencia social que aportaban experiencias similares desarrolladas en Europa y con las orientaciones del médico René Sand, secretario de Cruz Roja Internacional y fundador de los primeros cursos de Servicio Social en Europa. La carrera duraba dos años y sus profesionales se comprometían a desempeñarse al menos dos años en instituciones dependientes de la Junta Nacional de Beneficencia. El plan de estudios contemplaba asignaturas de derecho y economía política; profilaxis e higiene; protección a la infancia; alimentación y dietética; atención de enfermos y heridos; legislación de higiene y beneficencia; organización de la beneficencia pública y medicina legal. La práctica profesional consideraba visitas a instituciones de salud, para conocer los problemas sociales existentes, los recursos disponibles y las acciones asistenciales y educativas que podían desarrollarse en ese marco. Asimismo, la Escuela era responsable de la Oficina de Información de Asistencia Social de la Junta Nacional de Beneficencia, cen- tralizando la información social de la población y derivando a las instituciones correspondientes, para evitar doble prestación. Ya en enero de 1927 todas las organizaciones de la Junta Nacional de Beneficencia, tales como hospitales, servicios de atención de la desnutrición y mortalidad infantil ("Gota de Leche") y orfanatos contaban con una Oficina de Servicio Social.

En 1941, la Junta Nacional de Beneficencia resolvió sustituir el nombre de "visitadora social" por el título de "asistente social". El 3 de mayo de 1945, la Escuela tomó el nombre "Dr. Alejandro del Río", en homenaje a su fundador. En 1952, la Escuela pasó a depender del Servicio Nacional de Salud, al reorganizarse la atención de salud pública en Chile. En 1970 fue adscrita a la Universidad de Chile, permaneciendo hasta 1980, año en que fue reasignada al Instituto Profesional de Santiago, institución pública de educación superior creada por la Reforma Universitaria de aquel año, que recibió a las escuelas de la Universidad de Chile que perdieron el rango universitario. En 1993, se creó la Universidad Tecnológica Metropolitana como heredera legal del Instituto Profesional de Santiago, institucionalidad que acoge a la Escuela de Trabajo Social depositaria de la herencia formativa de aquella pionera fundación. En el año 2005, se restituyó el rango universitario a la profesión, oficializando su nueva denominación correspondiente a "trabajador social" y "trabajadora social”, conforme a los estándares internacionales vigentes ${ }^{2}$.

Al revisar en retrospectiva los avances de trabajo social obtenidos desde sus días fundacionales, se observa un importante desarrollo del acervo especializado asociado a criterios técnicos de urgencia, pertinencia y oportunidad de la intervención social en salud, constituyendo límites que dotan de exclusividad al desempeño de la profesión, considerada experta en la ayuda social. Su legitimidad está basada en normativas ministeriales vigentes a lo largo de su historia profesional y en los contextos de trabajo sanitario en los que ha colaborado. Con 90 años de trayectoria, el trabajo social chileno ha amplificado su quehacer profesional sumándose a diversos ministerios e instituciones públicas y privadas. Sin embargo, su profundo vínculo con salud se ha mantenido, estimándose que $40 \%$ del colectivo profesional se desempeña en el sector ${ }^{3}$.

Se reconoce como aporte profesional la incor- 
poración de la dimensión social en el tratamiento de problemas y necesidades sanitarias de la población, atesorando a lo largo de nueve décadas un valioso acervo de acciones profesionales de carácter asistencial, promocional, educativo, organizativo y de desarrollo social orientadas a colaborar en dicha tarea. Su progresiva especialización en salud se fundamenta en los avances del conocimiento científico tecnológico y en las renovadas propuestas conceptuales aportadas por los marcos interpretativos de las ciencias de la salud y de las ciencias sociales, consolidando un enfoque comprensivo de atención biopsicosocial que reconoce la multi causalidad de factores biológicos, sociales, económicos, culturales, territoriales, políticos y ambientales en los problemas sanitarios de la población. En ese marco, el trabajo social contribuye a la búsqueda de una mayor humanización en la atención del sistema de salud chileno.

El Dr. Alejandro del Río falleció el 5 de febrero de 1939. Sin embargo, su legado para el trabajo social chileno es imperecedero. Su tarea visionaria es rememorada permanentemente en las cátedras universitarias dictadas en Chile y en el continente. Su impronta inicial permanece actualmente en la formación profesional vinculada a contenidos especializados de políticas públicas de salud en atención primaria y hospitalaria, demografía y epidemiología, protección social, gestión de calidad en salud, participación comunitaria en salud, salud familiar y salud mental. La profesión tan entusiastamente promovida por el Dr. Alejandro del Río y respaldada por la Junta Nacional de Beneficencia Pública y Asistencia Social se convirtió en la primera carrera universitaria de ciencias sociales de Chile, contribuyendo a lo largo de su trayectoria al reconocimiento de la salud como
Derecho Humano fundamental y a la búsqueda de mejores condiciones sanitarias para la población, con especial atención en aquellas de menores recursos, preservando la misión central de profundo compromiso social que le fuera encomendada por su fundador en 1925.

Patricia Castañeda M. ${ }^{1, a}$, Ana María Salamé C. ${ }^{2, a}$ ${ }^{1}$ Escuela de Trabajo Social. Universidad de Valparaíso. Valparaíso, Chile.

${ }^{2}$ Departamento de Trabajo Social. Universidad de La Frontera. Temuco, Chile. ${ }^{a}$ Trabajadora Social. Doctora en Ciencias de la Educación. Universidad de Barcelona, España.

\section{Referencias}

1. Castañeda P, Salamé AM. Profesionalidad del Trabajo Social chileno. Tradición y Transformación. Temuco. Ediciones Universidad de La Frontera. 2012. p. 26.

2. República de Chile. Ley No 20.054 del 6 de septiembre de 2005. Modifica la Ley No 18.962 Orgánica Constitucional de Enseñanza restableciendo la exclusividad universitaria del Trabajo Social. Santiago de Chile. Diario Oficial de Chile. Veintisiete de septiembre de 2005. p. 1.

3. Cerda J, Ramírez N. Estudio Nacional de Competencias de los Trabajadores Sociales. Santiago de Chile. Ediciones UTEM, 2006. p. 124.

Correspondencia a:

Dra. Patricia Castañeda Meneses.

Avda. Colón 2128 Valparaíso, Chile.

Teléfono: 322508653.

patricia.castaneda@uv.cl 